\title{
Pengembangan Sistem Informasi Pelayanan Desa Berbasis Web Dengan Metode Prototyping Pada Desa Leran
}

\author{
Agung Kurniawan, Muhammad Chabibi, Renny Sari Dewi \\ Departemen Sistem Informasi, Universitas Internasional Semen Indonesia, Gresik, Indonesia \\ Email: 1agung.kurniawan16@student.uisi.ac.id, ${ }^{2}$ muhammad.chabibi16@student.uisi.ac.id, ${ }^{3}$ renny.dewi@uisi.ac.id
}

Submitted 30-12-2020; Accepted 15-01-2020; Published 15-02-2020

\begin{abstract}
Abstrak
Pelayanan administrasi berbasis web saat ini bukan hanya untuk pemerintahan di tingkat kota atau daerah saja, namun saat ini desa juga membutuhkan hal tersebut untuk menunjang kegiatan pemerintahannya. Menurut UU Nomor 6 tahun 2014 desa adalah kesatuan masyarakat hukum yang memiliki batas wilayah yang berwenang untuk mengatur dan mengurus urusan pemerintahan, kepentingan masyarakat setempat berdasarkan prakarsa masyarakat, hak asal usul, dan/atau hak tradisional yang diakui dan dihormati dalam sistem pemerintahan Negara Kesatuan Republik Indonesia. Pada era teknologi saat ini sebuah layanan untuk desa sudah banyak yang menggunakan dan memanfaatkan teknologi informasi agar proses pelayanan menjadi lebih mudah, transparan dan cepat. Untuk itu pada penelitian kali ini kami berkesempatan untuk mengembangkan sebuah Sistem Informasi Pelayanan Desa berbasis web di desa Leran, dalam pengembangan sistem kali ini kami menggunakan metode prototyping. Sistem ini nantinya akan memiliki berberapa fitur, di antaranya adalah: pembuatan laporan mandiri, pengajuan surat pengantar dari desa sacara online, pembuatan biodata masyarakat desa, dan juga memuat profil desa Leran. Hasil dari penilitian ini adalah sistem informasi pelayanan desa yang dapat membantu pekerjaan para pegawai pemerintahan di desa Leran, dan juga memudahkan masyarakat desa dalam medapatkan informasi tentang layanan ataupun informasi lainnya di desa Leran.
\end{abstract}

Kata Kunci: Web, Prototyping, Desa, Layanan, Administrasi

\begin{abstract}
Current web-based administrative services are not only for government at the city or regional level, but now the village also needs it to support its government activities. According to Law No. 6 of 2014 the village is a legal community unit that has the territorial boundaries that are authorized to regulate and administer government affairs, the interests of the local community based on community initiatives, original rights, and / or traditional rights that are recognized and respected in the Republic of the Republic of Republic's government system. Indonesia. In the current technological era, there are many services for villages that use and utilize information technology so that the service process becomes easier, more transparent and faster. For this reason, in this study we had the opportunity to develop a webbased Village Service Information System in Leran village, in developing the system this time we used a prototyping method. This system will have several features, including: making independent reports, submitting a letter of introduction from the village and online, making a biodata of the village community, and also containing the profile of the village of Leran. The results of this research are a village service information system that can help the work of government officials in the village of Leran, and also facilitate the villagers in obtaining information about services or other information in the village of Leran.
\end{abstract}

Keywords: Web, Prototyping, Villages, Services, Administration

\section{PENDAHULUAN}

Penyelenggaraan pelayanan masyarakat merupakan upaya negara untuk memenuhi kebutuhan dasar dari hak-hak setiap warga negara atas barang, jasa, dan pelayanan administrasi yang disediakan oleh penyelenggara pelayanan publik. Terkait dengan pelayanan masyarakat dimaksud, Undang-Undang Dasar 1945 mengamanatkan kepada negara untuk memenuhi kebutuhan dasar setiap warga negara demi kesejahteraannya, sehingga efektivitas penyelenggaraan suatu pemerintahan sangat ditentukan oleh baik buruknya penyelenggaraan pelayanan masyarakat. Disadari bahwa kondisi penyelenggaraan pelayanan masyarakat saat ini masih dihadapkan pada sistem pemerintahan yang belum efektif dan efisien serta kualitas sumber daya manusia aparatur yang belum memadai. Hal ini terlihat dari masih banyaknya keluhan dan pengaduan dari masyarakat baik secara langsung maupun melalui media massa, terkait dengan prosedur yang berbelit-belit, tidak ada kepastian jangka waktu, biaya yang harus dikeluarkan, persyaratan yang tidak transparan, petugas yang tidak profesional, sehingga menimbulkan citra yang kurang baik terhadap pemerintah [1].

Selaras dengan keluhan masyarakat secara umum terhadap pelayanan instansi pemerintahan desa, masyarakat di desa Leran juga merasa kurangnya informasi tentang pelayanan administrasi kependudukan pemerintahan desa. Masalah ini timbul dikarenakan pelayanan adminstrasi kependudukan di desa tersebut masih menggunakan cara yang manual untuk mengelola data tertulis dan metode pengarsipan sebagai penyimpanan datanya. Hal itu menyebabkan pendataan penduduk atau pelayanan administrasi secara umum membutuhkan waktu yang lebih lama dan terkadang data manual yang ada sudah tidak akurat lagi untuk saat ini. Di sisi lain keragaman masyarakat mempengaruhi aspirasi, tingkat kebutuhan dan kemampuannya, namun masyarakat desa Leran memiliki kesamaan harapan dan keinginan terhadap pelayanan di desa tersebut. Seluruh masyarakat desa berharap terhadap pelayanan yang cepat, handal, transparan, dan dapat dipercaya.

Pada penelitian sebelumnya yang dilakukan oleh Andreas dan Ahmad dengan judul Sistem Informasi Berbasis Web Pada Desa Tresnomaju Kecamatan Negerikaton Kab. Pesawaran, tujuan dari penelitian tersebut adalah untuk meningkatkan kualitas pelayanan publik. Suatu penyampaian informasi menggunakan sebuah aplikasi berbasis web akan lebih mudah dalam menerapkan e-government pada Desa Tresnomaju, dan agar dapat mempublikasikan ke masyarakat luas serta memudahkan masyarakat mendapatkan informasi yang dibutuhkan setiap saat hanya dengan menggunakan komputer yang 
sudah terkoneksi oleh internet. Dengan adanya sistem yang baru, maka dapat meningkatkan kemajuan dan kualitas sumber daya yang ada di Desa Tresnomaju dikarenakan informasi yang lebih mudah diketahui dan diakses oleh masyarakat luas [2].

\section{METODE PENELITIAN}

\subsection{Metode Pengembangan Sistem}

Metode pengembangan sistem yang digunakan untuk membangun sistem informasi ini adalah metodologi prototyping. Ogedebe, dkk (2012), menyampaikan bahwa prototyping merupakan metode pengembangan perangat lunak, yang berupa model fisik kerja sistem dan berfungsi sebagai versi awal dari sistem. Dengan metode prototyping ini akan dihasilkan prototype sistem sebagai perantara pengembang dan pengguna agar dapat berinteraksi dalam proses kegiatan pengembangan sistem informasi. Agar proses pembuatan prototype ini berhasil dengan baik adalah dengan mendefinisikan aturan-aturan pada tahap awal, yaitu pengembang dan penguna harus satu pemahaman bahwa prototype dibangun untuk mendefinisikan kebutuhan awal. Prototype akan dihilangkan atau ditambahkan pada bagiannya sehingga sesuai dengan perencanaan dan analisis yang dilakukan oleh pengembang sampai dengan ujicoba dilakukan secara simultan seiiring dengan proses pengembangan [3].

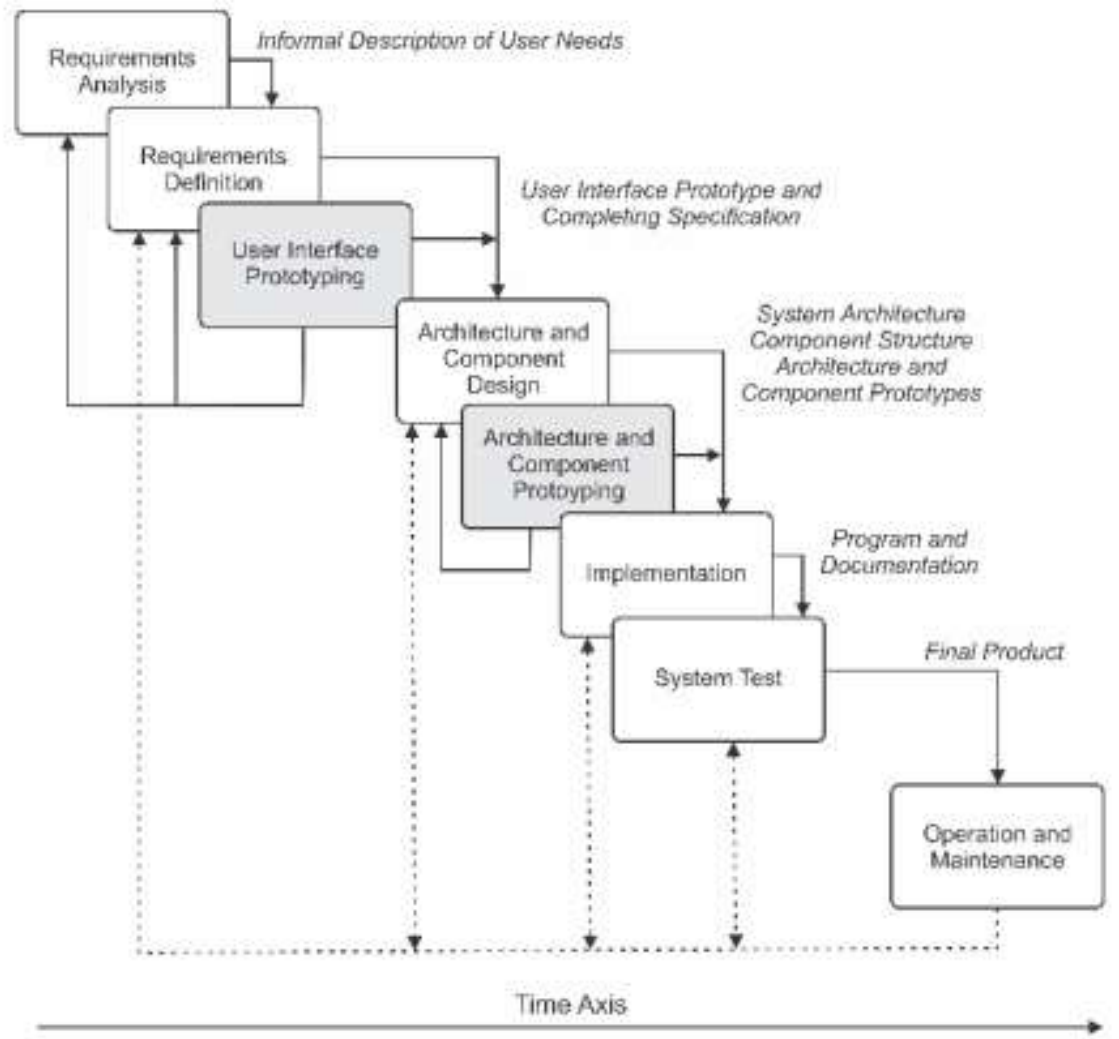

Gambar 1. Alur Proses Metode Prototyping

Gambar 1 ini menjelaskan mengenai alur pengembangan sistem dengan menggunakan metode Prototyping- Oriented Software. Pada tahap pertama, dilakukan analisis kebutuhan dan pendefinisian kebutuhan. Kebutuhan yang dimaksudkan disini adalah kebutuhan pelanggan/pengguna. Selanjutnya pada tahap kedua dilakukan pembuatan prototype dari aplikasi yang akan dibangun, mulai dari user interface prototyping dan dilanjutkan hingga penyusunan arsitektur dan komponenkomponen yang berkaitan dengan aplikasi yang akan dibangun. Selanjutnya dilakukan pengembangan sistem, dimana aplikasi akan dibangun sesuai dengan prototype yang telah dibuat sebelumnya, dan setelah aplikasi berhasil dibuat sesuai dengan kebutuhan maka dilakukan proses pengujian aplikasi sebelum aplikasi tersebut diimplementasikan [4].

\subsection{Objek Penelitian}

Objek pada penilitian ini adalah Kantor Kelurahan Desa Leran yang berada di Kecamatan Manyar Kabupaten Gresik, dan seluruh pegawai kelurahan Desa Leran yang bertanggungjawab untuk mengelola dan melaksanakan pelayanan kepada masyarakat desa Leran. Data yang mendukung dalam penelitian ini adalah data primer dan data sekunder, yaitu :

a. Data Primer adalah data yang diperoleh langsung dari wawancara di kantor kelurahan desa Leran.

b. Data Sekunder adalah data yang diperoleh dengan membaca dan mempelajari refrensi yang berkaitan dengan penilitian yang sedang dilakukan [5]. 


\section{ANALISA DAN PEMBAHASAN}

\subsection{Analisis Proses Bisnis}

Proses bisnis atau alur kerja pada sistem ini nantianya akan mengacu pada proses bisnis yang sudah ada saat ini di desa Leran.

a. Diagram Aktivitas

Alur kerja pada sistem pelayanan desa saat ini akan dijelaskan dengan menggunakan activity diagram atau diagram aktivitas. Berberapa ktivitas utama administrasi kependudukan yang berjalan di kantor kelurahan Desa Leran di antaranya adalah:

1. Berikut ini adalah activity diagram untuk pengajuan surat pengantar pembuatan kartu keluarga (KK). Untuk lebih jelasnya dapat dilihat pada Gambar 2.

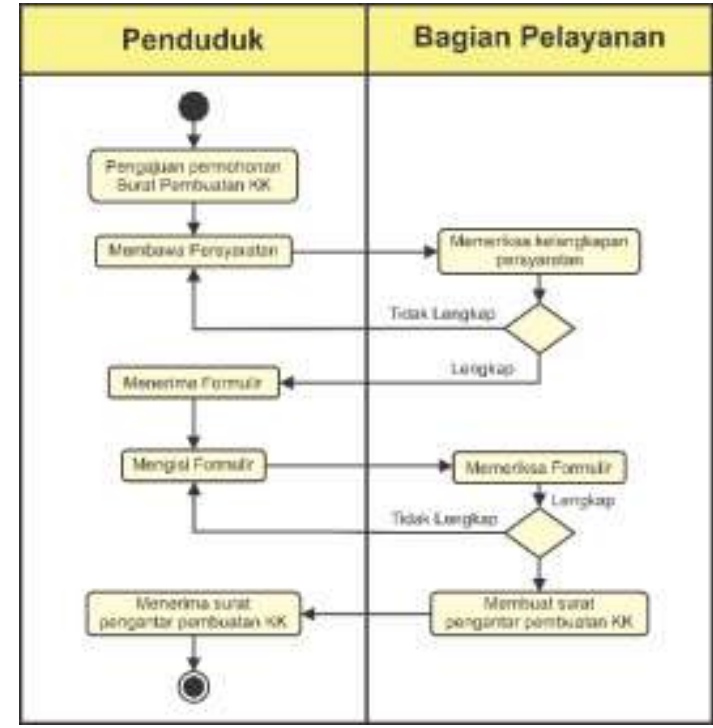

Gambar 2. Activity Diagram Pengajuan Surat Pengantar Pembuatan KK

2. Berikut ini adalah activity diagram untuk pengajuan surat pengantar pembuatan kartu tanda penduduk (KTP). Untuk lebih jelasnya dapat dilihat pada Gambar 3.

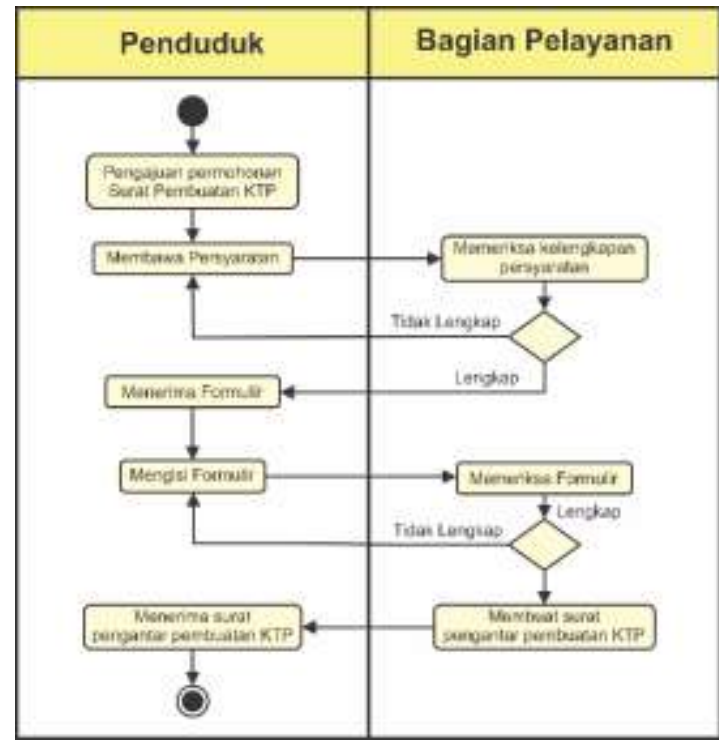

Gambar 3. Activity Diagram Pengajuan Surat Pengantar Pembuatan KTP

3. Berikut ini adalah activity diagram unttuk pengajuan pembuatan surat keterangan kelahiran (SKKL). Untuk lebih jelasnya dapat dilihat pada Gambar 4. 


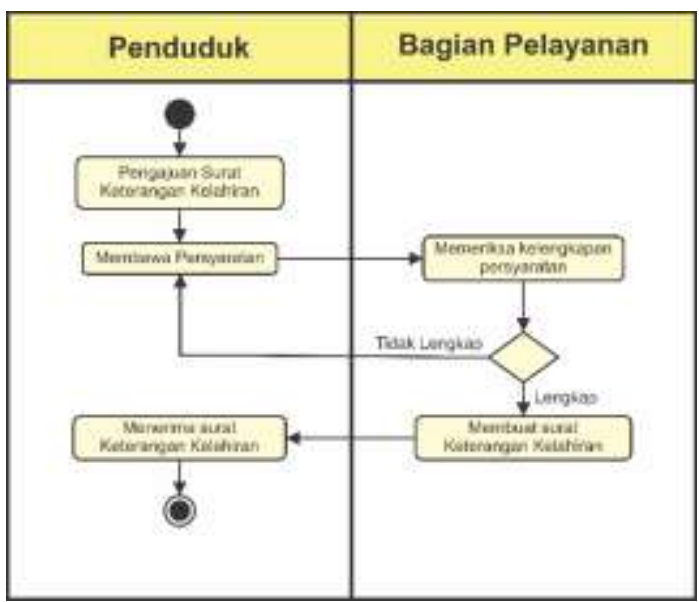

Gambar 4. Activity Diagram Pengajuan Pembuatan SKKL

\subsection{Analisa Kebutuhan}

Tahap analisa kebutuhan dilaksanakan untuk mendapatkan informasi yang dibutuhkan, model serta spesifikasi mengenai perangkat lunak atau software yang dibutuhkan oleh pengguna. Keterlibatan kedua belah pihak yaitu klien dan pembuat aplikasi sangat dibutuhkan dalam tahap ini [5]. Pada tahapan ini dilakukan analisa kebutuhan untuk sistem informasi pelayanan desa dengan langsung wawancara dengan para Perangkat desa Leran yang sedang bertugas di kantor kelurahan desa Leran.

a. Kebutuhan Data

Data dari porses pelayanan adminitrasi di desa Leran didapatkan saat melakukan wawancara langsung dengan para perangkat atau petugas di kantor kelurahan Desa Leran. Kemudian dari hasil wawancara tersebut dianalisis, dan akhirnya disimpulkan bahwa data yang dibutuhkan saat pengembangan aplikasi ini, di antaranya adalah:

1. Data wilayah, merupakan data yang berisi tentang luas wilayah, batas wilayah, letak koordinat, dan juga alamat desa yang meliputi: Provinsi, kabupaten, dan juga tingkat bawah yaitu dusun.

2. Data Induk Kependudukan, adalah data yang berisi regristasi penduduk pada Kartu Keluarga (KK).

3. Data Penduduk merupakan induk data warganegara baik WNI (Warga Negara Indonesia) maupun WNA (Warga Negara Asing) yang ada di desa Leran. Data penduduk ini dirancang secara dinamis untuk mengantisipasi terjadinya perubahan aturan pencatatan dalam kependudukan. Misal data pekerjaan, saat ini secara resmi dalam aturan kependudukan macam kelompok pekerjaan sebanyak 16. Tidak hanya kelompok pekerjaan, data pendukung lainnya juga dirancang sedinamis mungkin. Data tersebut antara lain Agama, Akseptor KB, Golongan Darah, Status Hubungan dalam Keluarga, Kelainan Khusus, dan Pendidikan [6].

4. Data dari rekap surat dan formulir surat, data ini nantinya akan digunakan sebagai acuan untuk pembuatan form untuk fiur cetak surat pada sistem layanan.

\subsection{Analisa Kebutuhan}

Setelah melakukan wawancara dan analisa dengan para perangkat desa di kantor kelurahan desa Leran, maka disimpulkan bahwa dalam pengembangan sistem informasi kali ini membutuhkan berberapa aspek pendukung, dan di antaranya adalah:

a. Hardware

Sistem informasi pelayanan desa ini nantinya diharapkan dapat berjalan di sistem yang seminimal mungkin agar para perangkat desa dan masyarakat dapat mudah untuk mengaksesnya, dengan spesifikasi minimal menggunkanan processor Intel Pentium 4 atau AMD A4, dan RAM 1 GB sudah bisa digunakan untuk menjalankan sistem ini. Dan dari hasil analisa di kantor kelurahan Desa Leran komputer yang ada di kantor tersebut memiliki spesifikasi: processor Intel Core i3, dan RAM 4 GB yang memungkinkan untuk menjalankan sistem informasi pelayanan desa ini dengan sangat lancar.

b. Software

Untuk merancang dan mengembangkan sistem informasi pelayanan desa ini dibutuhan berberapa tools atau software di antaranya adalah: OS Windows 7, XAMPP, Sublime Text 3, Chrome Browser, Bostrap v4 dan Framework OpenSID 19.10 .

\subsection{Perancangan Sisem}

Tahap perancangan ini dilakukan bertujuan untuk menghubungkan antara kebutuhan pengguna dengan proses implementasi oleh pengembang agar sesuai dengan kebutuhan yang dibutuhkan oleh pengguna [7]. Pada tahap ini akan dimulai tahap untuk perancangan sistem dengan use case diagram, dan perancangan database dengan menggunakan ERD.

a. Use Case Diagram

Use case diagram ini merupakan suatu pemodelan untuk mendeskripsikan sebuah interaksi dari satu atau lebih aktor dengan fungsi-fungsi atau fitur di dalam sistem yang akan berjalan nantinya, untuk lebih jelasnya bias dilihat pada gambar 5 . 


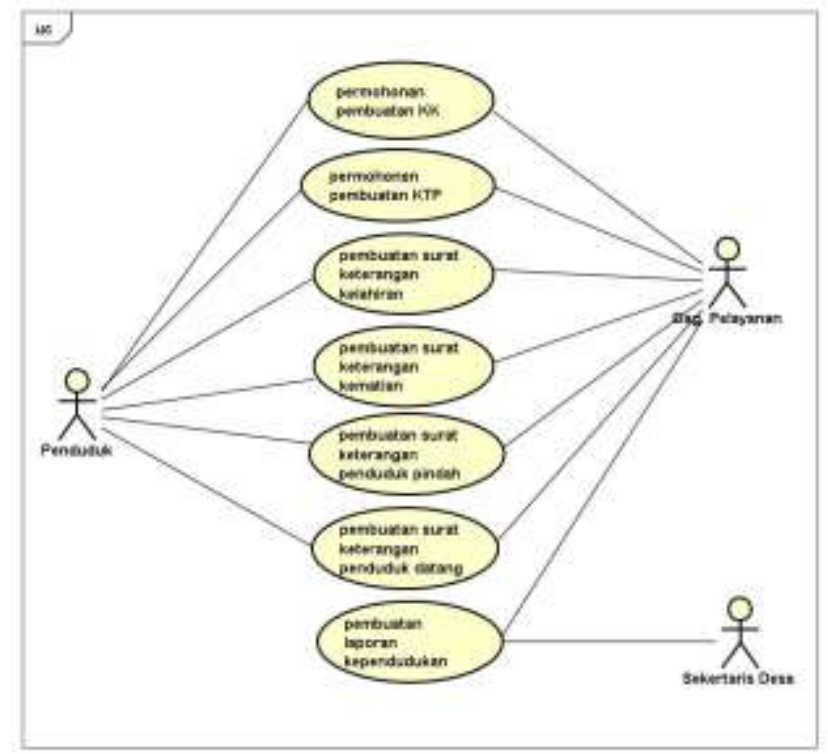

Gambar 5. Use Case Diagram Sistem

Tabel 1 adalah deskripsi pendefinisian aktor pada Use Case Diagram sistem informasi pelayanan desa yang akan berjalan di kantor kelurahan desa Leran:

Tabel 1. Definisi Aktor Pada Sistem

\begin{tabular}{|c|c|c|}
\hline No & Aktor & Deskripsi \\
\hline 1 & Penduduk & $\begin{array}{l}\text { Berperan sebagai user dan masyarakat desa Leran yang } \\
\text { melakukan permohonan pembuatan surat pengantar } \\
\text { pembuatan KK, surat pengantar pembuatan KTP, surat } \\
\text { keterangan kelahiran, surat keterangan kematian, pembuatan } \\
\text { surat keterangan penduduk datang, pindah atau keluar. }\end{array}$ \\
\hline 2 & Bag. Pelayanan & $\begin{array}{l}\text { Berperan sebagai admin dan orang yang bertugas melakukan } \\
\text { pelayanan kepada masyarakat desa Leran untuk memproses } \\
\text { pembuatan surat pengantar pembuatan KK, surat pengantar } \\
\text { pembuatan KTP, surat keterangan kelahiran, surat keterangan } \\
\text { kematian, pembuatan surat keterangan penduduk datang, } \\
\text { pindah atau keluar. }\end{array}$ \\
\hline 3 & Sekretaris Desa & $\begin{array}{l}\text { Berperan sebagai admin dan Orang yang bertugas dalam } \\
\text { proses pembuatan laporan penduduk di setiap bulan. }\end{array}$ \\
\hline
\end{tabular}

Tabel 2 adalah deskripsi dari use case diagram pada sistem informasi pelayanan desa yang akan berjalan di kantor kelurahan Desa Leran:

Tabel 2. Definisi Use Case Pada Sistem

\begin{tabular}{|c|c|c|}
\hline No & Use Case & Deskripsi \\
\hline 1 & $\begin{array}{l}\text { Permohonan pembuatan } \\
\text { KK }\end{array}$ & $\begin{array}{l}\text { Merupakan proses pengisian formulir oleh } \text { user } \\
\text { (Penduduk) pada fitur cetak surat pengantar pembuatan } \\
\text { KK secara online di dalam sistem. }\end{array}$ \\
\hline 2 & $\begin{array}{l}\text { Permohonan pembuatan } \\
\text { KTP }\end{array}$ & $\begin{array}{l}\text { Merupakan proses pengisian formulir oleh } \text { user } \\
\text { (Penduduk) pada fitur cetak surat pengantar pembuatan } \\
\text { KTP secara online di dalam sistem. }\end{array}$ \\
\hline 3 & $\begin{array}{l}\text { Permohonan pembuatan } \\
\text { surat keterangan kelahiran }\end{array}$ & $\begin{array}{l}\text { Merupakan proses pengisian formulir oleh user } \\
\text { (Penduduk) pada fitur cetak surat keterangan kelahiran } \\
\text { secara online di dalam sistem. }\end{array}$ \\
\hline 4 & $\begin{array}{l}\text { Permohonan pembuatan } \\
\text { surat keterangan kematian }\end{array}$ & $\begin{array}{l}\text { Merupakan proses pengisian formulir oleh } \text { user } \\
\text { (Penduduk) pada fitur cetak surat keterangan kematian } \\
\text { secara online di dalam sistem. }\end{array}$ \\
\hline 5 & $\begin{array}{l}\text { Permohonan pembuatan } \\
\text { surat keterangan penduduk } \\
\text { datang }\end{array}$ & $\begin{array}{l}\text { Merupakan proses pengisian formulir oleh } \text { user } \\
\text { (Penduduk) pada fitur cetak surat keterangan penduduk } \\
\text { datang secara online di dalam sistem. }\end{array}$ \\
\hline 6 & $\begin{array}{l}\text { Permohonan pembuatan } \\
\text { surat keterangan penduduk } \\
\text { pindah }\end{array}$ & $\begin{array}{l}\text { Merupakan proses pengisian formulir oleh user } \\
\text { (Penduduk) pada fitur cetak surat keterangan penduduk } \\
\text { pindah secara online di dalam sistem. }\end{array}$ \\
\hline
\end{tabular}


Membuat laporan kependudukan
Merupakan proses pengolahan data penduduk yang terdapat dalam database sistem untuk membuat secara otomatis laporan kependudukan di setiap bulan.

\section{IMPLEMENTASI}

Setelah data dan semua hal yang dibutuhkan maka kami melanjutkan ke tahap implementasi Sistem Informasi Pelayanan Desa Berbasis Web pada Desa Leran.

\subsection{Entity Relationship Diagram (ERD)}

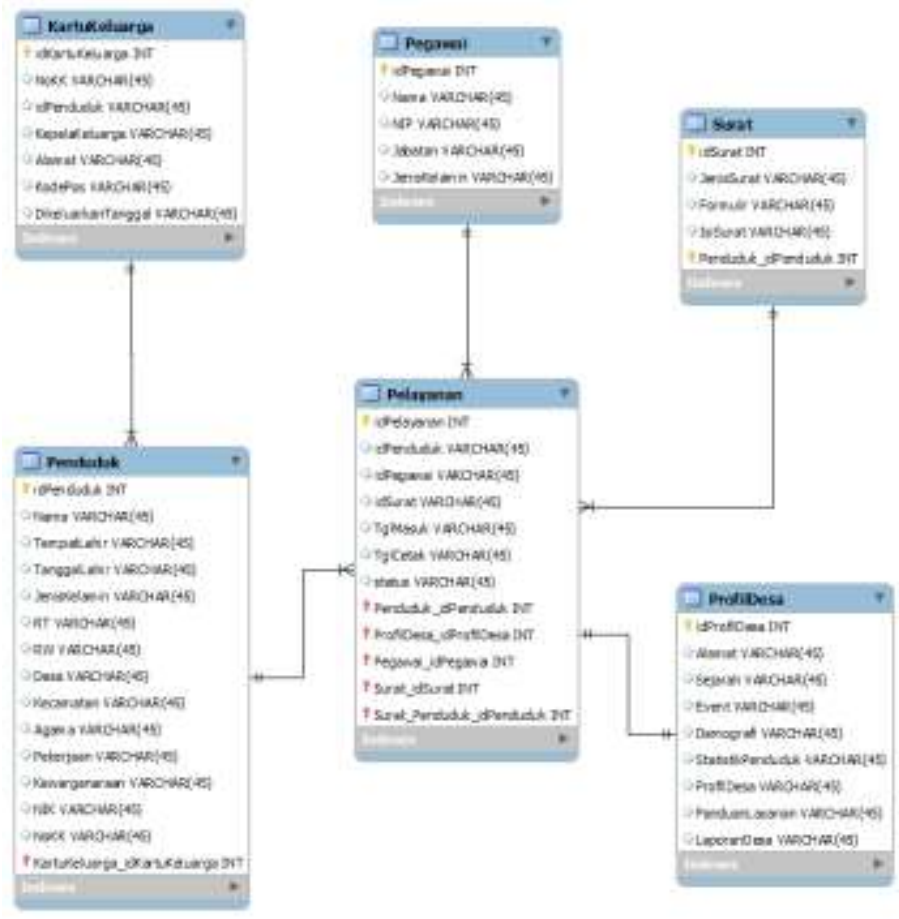

Gambar 6. Design ERD System

Pada Gambar 6 dapat dilihat secara kasar desain database untuk sistem ini nantinya akan memiliki berberapa entitas utama, yaitu: penduduk, surat, pegawai, profil desa, pelayanan, dan kartu keluarga (KK).

\subsection{Pengembangan Prototype}

Pada tahap ini dilakukan tahap pembangunan prototype dimana kebutuhan client, diagram-diagram pemodelan, desain perancangan antarmuka akan diterjemahkan ke dalam bahasa pemrograman dan akan menghasilkan sebuah prototype sistem informasi pelayanan desa di desa Leran.

\subsection{Evaluasi Client Terhadap Prototype}

Pengujian ini dilakukan oleh para perangkat desa yang berada di kantor kelurahan desa Leran, tahap ini sangat dibutuhkan untuk mengetahui apakah prototype sistem yang sudah kita buat terdapat kelemahan atau tidak, dan dari hasil pengujian oleh perangkat desa mereka menyatakan bahwa prototype sistem ini sudah memenuhi sebagian besar ekspetasi mereka, dan juga sudah lancar berjalan di komputer yang ada di kantor kelurahan desa Leran. Namun kami mendapat berberapa masukan dari para perangkat desa Leran, bahwa mereka mengingkan sistem informasi pelayanan desa ini nantinya mempunyai antarmuka yang menarik, dan mudah digunakan oleh masyarakat awam, agar para masyarakat desa Leran dan perangkat desa yang awam dengan dunia IT dapat secara optimal untuk memanfaatkan sistem ini nantinya.

\subsection{Perbaikan Prototype dan Implementasi Akhir}

Perbaikan prototype ini dilakukan sesuai dengan permintaan dari client, dan jika sudah diperbaiki maka akan ditunjukkan dan diuji lagi oleh client sampai benar-benar tidak ada kesalahan atau kekurangan pada prototype sistem. Dan pada prototype sistem kali ini kami hanya mengubah sedikit di bagian desain antarmuka sistem. Dan jika prototype sistem sudah disetujui oleh client, maka kita akan melanjutkan ke tahap selanjutnya, yaitu implementasi akhir yang terdiri dari penginputan datadata yang dipelukan oleh sistem, sinkronisasi sistem dengan database, pembelian domain, meng-upload database dan file program ke hosting agar sistem bisa diakses secara online, dan yang terakhir adalah melakukan sosialisi dan pelatihan kepada 
para perangkat desa Leran dan juga masyrakat desa Leran tentang sistem informasi pelayanan desa yang sudah ada di desa Leran.

\subsection{Tampilan Antarmuka Sistem}

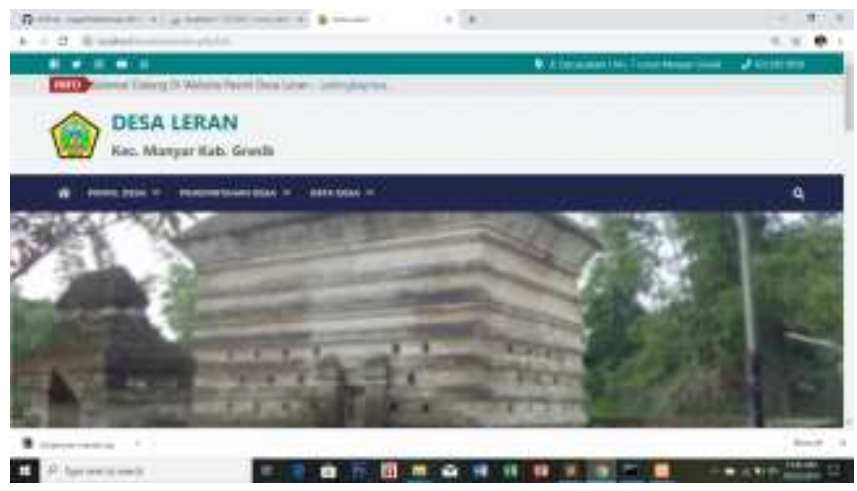

Gambar 7. Tampilan Antarmuka Halaman Awal

Pada Gambar 7 ini menampilkan halaman awal website dan terdapat berberapa foto desa Leran, profil desa, data desa dan juga data pemerintahan desa. Selain itu juga terdapat logo dan kontak yang bisa dihubungi apabila kita memerlukan bantuan.

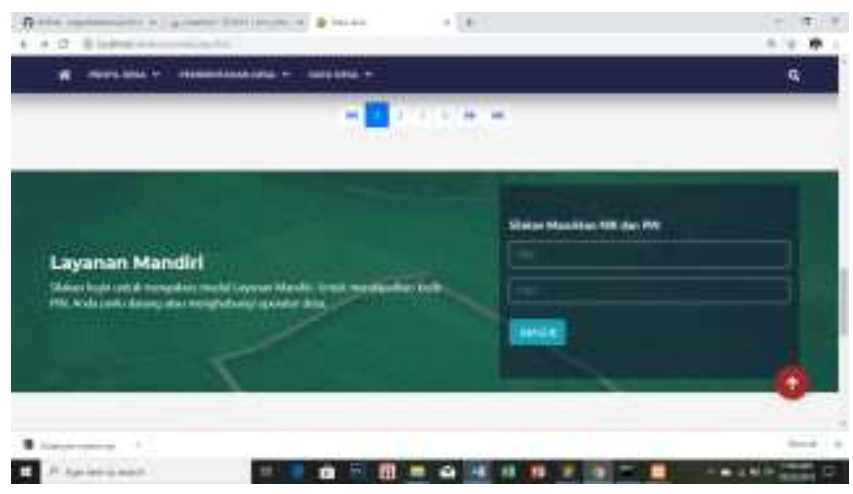

Gambar 8. Tampilan Antarmuka Halaman Login

Pada Gambar 8 ini menampilkan halaman login dan masyarakat diharuskan untuk mengisi NIK dan PIN agar dapat mengakses sistem informasi pelayanan desa ini.

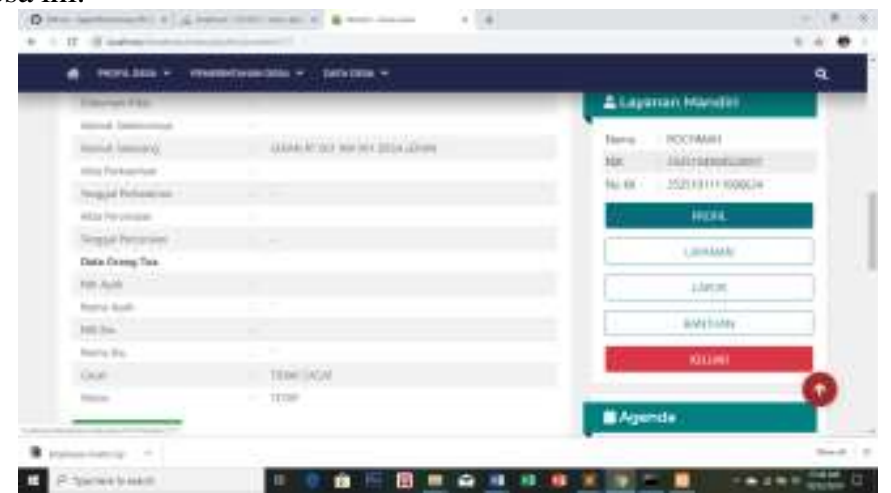

Gambar 9. Tampilan Antarmuka Halaman Menu Data Penduduk

Pada Gambar 9 ini menampilkan halaman data penduduk secara lengkap, dan juga terdapat informasi user yang mengakses sistem ini di bagian kanan sistem, selain itu ada berberapa menu pilihan di antaranya adalah profil, layanan, lapor, dan juga bantuan. 


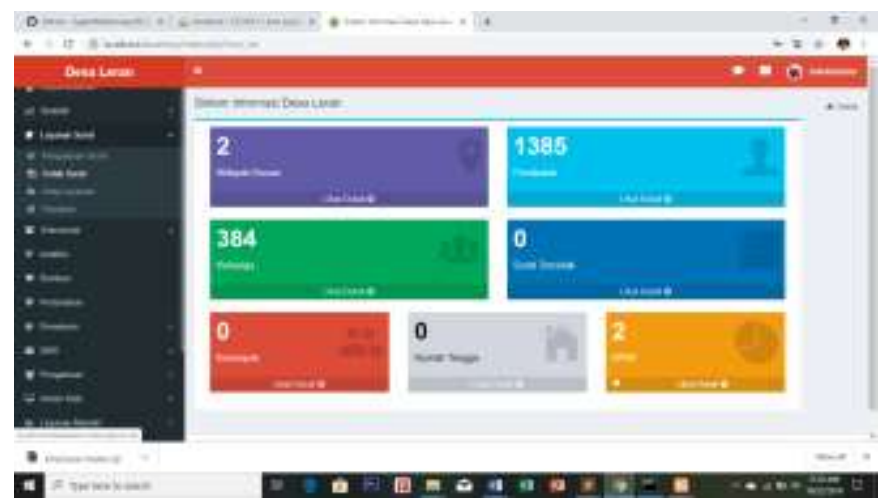

Gambar 10. Tampilan Antarmuka Pada User Admin

Pada Gambar 10 ini ditampilkan menu admin, dan menampilkan semua fitur dan menu yang ada pada sistem informasi layanan desa Leran. Selain itu admin juga berkewajiban untuk mengelola dan meng-update data yang ada di dalam sistem.

\section{KESIMPULAN}

Dari Penelitian yang telah dilakukan di kantor kelurahan desa Leran, maka dapat diambil berberapa kesimpulan, di antaranya adalah:

a. Permasalahan yang ada di desa Leran mengenai terbatasnya akses untuk informasi, dan juga belum tersedianya fasilitas yang cukup untuk masyarakat yang ingin mengetahui suatu informasi. Para masyarakat desa Leran terkadang harus datang terlebih dahulu ke kantor kelurahan desa Leran untuk mendapatkan informasi yang di cari.

b. Dengan adanya sistem informasi pelayanan desa di desa Leran ini, diharapkan masyarakat desa Leran dapat lebih mudah untuk mengakses informasi dan juga layanan tanpa harus datang langsung ke kantor kelurahan desa Leran.

c. Informasi yang ada dalam sistem dapat di akses oleh masyarakat desa Leran di setiap saat, karena sistem pelayanan tersebut berbasis web dan juga sudah dapat dikses secara online.

d. Sosialisasi kepada masyarakat sangat penting, agar sistem yang sudah dikembangkan ini dapat berjalan secara efektif dan efisien.

e. Perawatan dan juga evaluasi untuk sistem perlu dilakukan secara rutin, agar sistem yang sudah berjalan saat ini dapat selalu beradaptasi dengan perkembangan zaman dan juga perkembangan sistem administrasi di pemerintahan desa.

f. Sistem informasi pelayanan desa Leran ini sangat membantu tugas para perangkat desa terutama untuk masalah administrasi dan juga pengelolaan data penduduk di desa.

\section{REFERENCES}

[1] J. I. Vol, "Implementasi Sikades (Sistem Informasi Kependudukan Desa) Untuk Kemudahan Layanan Administrasi Desa Berbasis Web Mobile," J. Inform., vol. 8, no. 1, pp. 858-869, 2014.

[2] A. Andoyo and A. Sujarwadi, "Sistem Informasi Berbasis Web Pada Desa Tresnomaju Kecamatan Negerikaton Kab. Pesawaran Andreas Andoyo, M.T.I., Ahmad Sujarwadi STMIK Pringsewu - Lampung Jl. Wisma Rini No.09 Pringsewu.Telp/Fax.(0729)22240. www.stmikpringsewu.ac.id Email : andoyo@gmail.co,”J.TAM (Technology Accept. Model ), vol. 3,pp. 1-9, 2014

[3] D. Purnomo, "Model Prototyping Pada Pengembangan Sistem Informasi," JIMP - J. Inform. Merdeka Pasuruan, vol. 2, no. 2, pp. 54-61, 2017.

[4] A. A. Pradipta, Y. A. Prasetyo, and N. Ambarsari, "Pengembangan Web E-Commerce Bojana Sari Menggunakan Metode Prototype," e-Proceeding Eng., vol. 2, no. 1, pp. 1042-1056, 2015.

[5] S. Artikel, "Jurnal Nasional Teknologi dan Sistem Informasi Sistem Retribusi Parkir Sebagai Pengawasan Pendapatan Asli Daerah Kabupaten Cilacap," vol. 01, pp. 1-8, 2019.

[6] M. Anshori, A. Yosi, I. D. Fibrian, and M. Zainal, "Upaya Peningkatan Pelayanan Administrasi Kependudukan Menggunakan Teknologi Informasi : Rancang Bangun Sistem Informasi di Desa Sumbermulyo Kecamatan Jogoroto Kabupaten Jombang,” J. Ilm. Teknol. Sist. Inf., vol. 2, pp. 51-59, 2008.

[7] E. Satria, R. Cahyana, J. Algoritma, S. Tinggi, T. Garut, and M. Prototype, "PENGEMBANGAN APLIKASI ZAKAT BERBASIS ANDROID,” pp. $1-7$. 